\title{
Method for Procuring Specific Populations of Viable Human Prostate Cells for Research
}

\author{
Andrew H. Fischer, Abraham Philips, Panya Taysavang, Jesse K. McKenney, and \\ Mahul B. Amin \\ Department of Pathology (AHF, AP, PT, JKM, MBA), Emory University, Atlanta, Georgia
}

SUMMARY: A wider range of research can be conducted on viable tissue samples than on fixed or frozen samples. A major obstacle to studying viable prostate tissue samples is the inability to accurately identify cancer on direct examination of unembedded tissue. We used a dissecting microscope to identify cancer in unfixed prostate tissue samples stained on the cut surface with $0.5 \%$ aqueous toluidine blue. We measured the diagnostic accuracy of this technique in 25 consecutive prostatectomies, determined the viability of procured samples, and estimated the effect on final pathologic assessment. Both surfaces of a 3- to 5-mm thick cross-section taken midway between base and apex of the prostate were examined. A 4-mm punch biopsy was directed to one benign and one malignant area when clearly present. The dissecting microscope allowed clearcut recognition of carcinoma in 17 of the 25 cross-sections, and carcinoma was confirmed in all 17 (100\%). In 8 of 25 cases, no procurement was attempted because no carcinoma was evident in the one cross-section studied. Twenty of 25 cross-sections were adequate for benign tissue procurement; five of the cross-sections were not suitable for procurement because of the presence of extensive carcinoma or atrophy. Seventeen of the 20 were accurately diagnosed as benign (85\%); one showed pseudohyperplastic adenocarcinoma, one showed focal high-grade prostatic intraepithelial neoplasia, and one showed urothelial carcinoma in situ. Prostatic epithelium obtained with the technique remains viable and can be separated from stroma. The dissecting microscope technique appears to facilitate rather than interfere with accurate pathologic assessment: extraprostatic extension or positive margins were correctly identified during tissue procurement in three cases. The procedure takes only about 30 minutes. (Lab Invest 2001, 81:501-507).

$T$ he inability to diagnose prostate cancer accurately by gross examination puts a considerable constraint on prostate cancer research. Unlike cancers in other organs, gross diagnosis of prostate cancer has an overall accuracy of only about $50 \%$ (Furman et al, 1998). The accuracy of gross diagnosis is even lower in cases in which tumor volume is low (Furman et al, 1998) making it especially difficult to provide tissue for researchers to study early events in prostate cancer development. To accurately diagnose a prostate sample, microscopy is required, and microscopy in turn imposes limits on the types of research that can be performed.

Laser capture microdissection offers the potential for procuring a small number of precisely characterized cells (Suarez-Quian et al, 1999). However, microdissected samples have limited usefulness. First, the procured cells are nonviable, which hinders or precludes dynamic types of molecular studies. Such dynamic studies include time-lapse microscopy, metabolic labeling, mapping biochemical pathways, assessing protein-protein interactions, conventional cytogenetics, cell kinetic measurements, or measuring protein or RNA stability. Second, too few cells can be

Received November 22, 2000.

This work was supported in part by National Institutes of Health Grant 5R21CA 69764-04 awarded to MBA.

Address reprint requests to: Dr. Andrew H. Fischer, Department of Pathology, University of Massachusetts, UMASS Memorial Healthcare, 55 Lake Avenue North, Worcester, MA, 01655. E-mail: fischa01@ummhc.org procured to permit many types of biochemical studies, such as polyacrylamide gel electrophoresis, immunoblotting, or immunoprecipitations. Third, RNA-based studies from microdissected tissue require reverse transcription polymerase chain reaction (RT-PCR) amplification. Although informative cDNA libraries can be produced (Emmert-Buck et al, 2000) and methods for quantifying the number of transcripts from one or perhaps a few genes can be developed (Freeman et al, 1999), there are still significant barriers to being able to assure representative amplification of transcripts across the whole genome.

Existing techniques for procuring larger samples of characterized prostate tissue can theoretically threaten the ultimate pathologic assessment of the case, for example by interfering with assessment of resection margins or by procuring the entire tumor in cases with a low tumor volume (Bova et al, 1993; Furman et al, 1998; Wheeler and Lebovitz, 1994). The procured sample is typically frozen, and the diagnosis is verified by frozen section (Egevad, et al, 1998; Sakr et al, 1995). Unfortunately, freezing the sample prevents performance of dynamic types of molecular studies. In addition, bulk-frozen tissue contains an inseparable mixture of cell types, making it difficult for prostate cancer researchers to know if they are studying the cell that is evolving or the environment that is accommodating the evolution.

Fresh viable prostate tissue samples can be separated into stromal and epithelial cell fractions (Kassen et al, 1996; Sherwood et al, 1989; Webber, 1988). In 

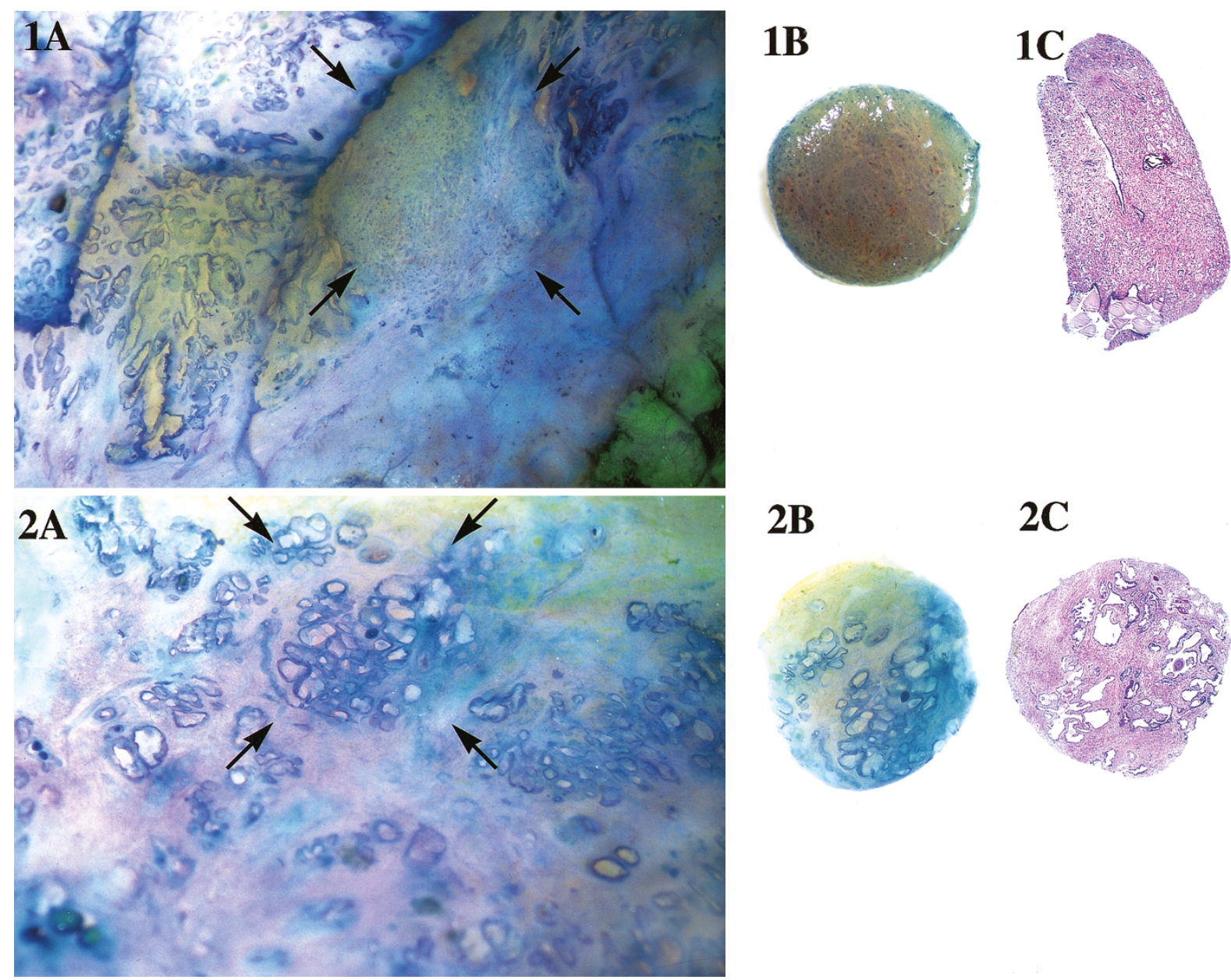

\section{B}

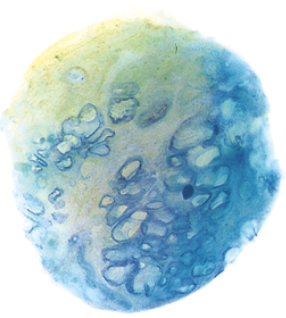

2C

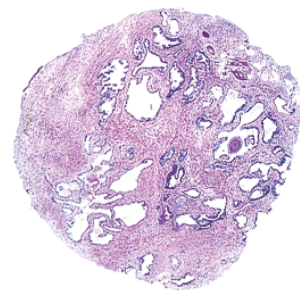

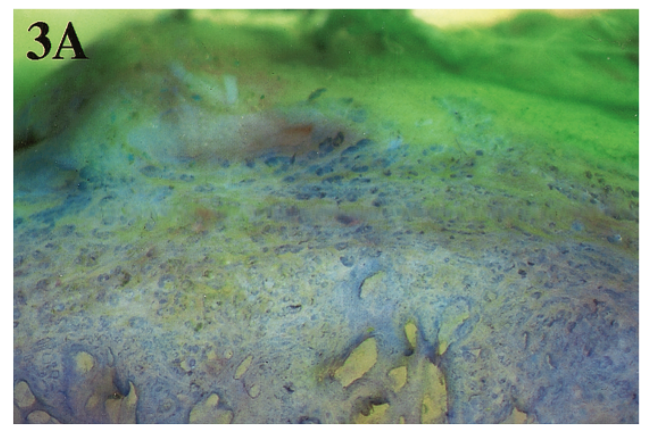
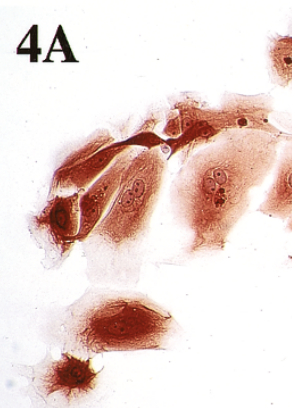

3B

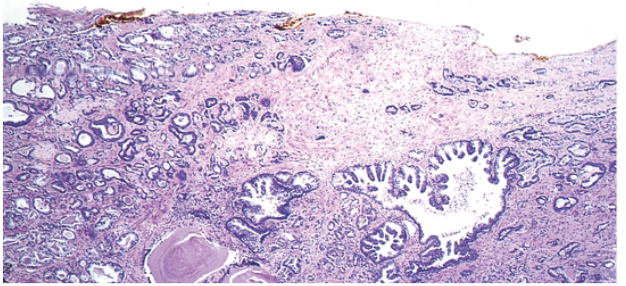

4B

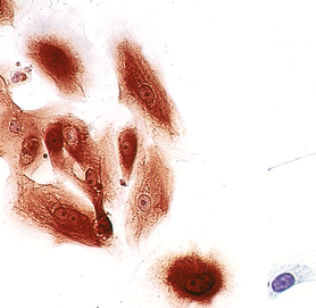

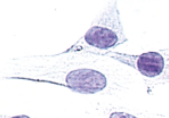

(29)

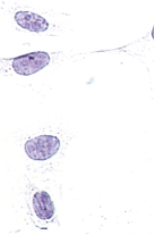

당

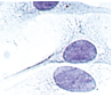

(2)

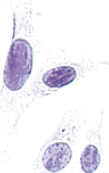

5

(ㄱ)

Figure 1.

Appearance of a small focus of prostatic adenocarcinoma in unfixed tissue under the dissecting microscope. A, Arrows outline an approximately 5-mm focus of prostatic adenocarcinoma. Carcinoma is characterized by haphazard growth of cells. Focally at least, these can be seen to form occasional small glands. The tumor focally infiltrates adjacent benign glands toward the upper right. The appearance suggests a Gleason Grade 3 to 4 pattern. Note that the nuclei do not stain particularly darkly. To the left of the carcinoma are some benign prostatic glands characterized by larger size and more intervening stroma. Toward the lower half, slightly to the right, is a relatively large area of prostatic stroma devoid of glands. Such an area, although designated benign, would obviously not be suitable for procuring norma 
theory, such bulk viable cell populations would be ideal for RNA work and would be suitable for studying stromal-epithelial interactions, biochemical analysis, comparative gene expression protocols, and the dynamic types of molecular studies described above. The problem is that it is extremely difficult to characterize unfrozen viable prostate tissue samples. Performance of frozen sections adjacent to a sample of fresh tissue is time consuming and extremely tedious in our experience. In addition, performing frozen sections around a viable sample seems particularly likely to interfere with final pathologic assessment. Another technique is to obtain cores of tissue and infer the diagnosis later based on the rim of tissue that surrounds the procured hole (Furman et al, 1998; Wheeler and Lebovitz, 1994). However, the accuracy of the diagnosis within the actual fresh, unfrozen tissues adjacent to the areas examined by frozen or permanent sections is incompletely documented (Wheeler and Lebovitz, 1994); for example, it is not clear whether tissues considered as benign contain prostatic intraepithelial neoplasia. Theoretically, touch prep cytology could help characterize a fresh, unfixed procured sample; but no estimates for the accuracy of this technique are available (Bova, et al, 1993; Wheeler and Lebovitz, 1994). Herein, we describe the accuracy of a technique for diagnosing unfixed, unfrozen prostatic tissue, and show that prostatic epithelium procured with the technique remains viable and separable from stromal cells.

\section{Results}

\section{Assessing the Accuracy of the Dissecting Microscope for Diagnosing Cancer and Benign Prostatic Tissue in Unfixed Tissue}

Toluidine blue stains nuclei darkly at the surface of unfixed tissue, allowing diagnostic low-magnification architectural patterns to be discerned with the aid of a dissecting microscope (Fischer and Bouc, 1991). Features of malignancy include small size of the prostatic glands, fused glands or cords of cells, infiltrative growth pattern, and lack of a lobular arrangement. Carcinoma may not stain darkly. Benign prostatic tissue has a circumscribed lobular architecture with large and relatively widely-spaced glands. This technique was applied to a single complete cross-section,
3- to 5-mm thick, from 25 consecutive radical prostatectomies (see "Materials and Methods"). Figure 1A shows the typical appearance of a focus of prostatic adenocarcinoma in a low-magnification dissecting microscope. Arrowheads outline a poorly circumscribed group of uniform, pale-staining small glands or fused cords of cells, approximately $5 \mathrm{~mm}$ in diameter. A 4-mm punch biopsy allows this area to be neatly procured under dissecting microscope guidance (Fig. 1B). The resulting biopsy (embedded at roughly 90 degrees to the original toluidine blue-stained surface) shows near complete replacement of the biopsy with tumor (Fig. 1C). The toluidine blue washes out during embedding and is not evident in the final paraffin section.

Another area of the same 3- to 5-mm thick complete cross-section of unfixed prostate tissue was suitable for procuring benign prostatic tissue, as shown in Figure 2. Benign tissue shows large, circumscribed glands. An area to be procured is outlined with arrows in Figure 2A. Figure 2B shows the procured plug of benign prostatic tissue and Figure $2 \mathrm{C}$ shows the corresponding paraffin section of the tissue plug.

The results of studying 25 radical prostatectomies are shown in Table 1. Unambiguous prostatic adenocarcinoma was evident under the dissecting microscope in 17 of 25 consecutive prostatectomies and was confirmed in all 17 resulting punch biopsies (100\%). In 8 of the 25 cases, no cancer was evident to biopsy in the single cross-section studied. In at least three of these cases, the absence of carcinoma is consistent with the absence of carcinoma in the whole prostate; three prostates were removed as part of a cystoprostatectomy for bladder cancer. In the other cases, the actual presence or absence of tumor in the 3- to 5-mm section examined is unknown because the remaining tissue was banked frozen.

Twenty of the 25 prostatectomies were adequate for procuring normal prostatic tissue; four cases were not suitable because carcinoma could be seen to essentially replace the entire peripheral zone. One case was unsuitable for procurement of normal prostate tissue because extensive atrophy was suspected and later confirmed in permanent sections. This case showed angular, uniformly medium-sized glands without an infiltrative pattern. Seventeen of the 20 (85\%) presumptively normal prostate tissue biopsies procured

prostate epithelium. The few spots of blue in this area correspond to blood vessels that tend to stain darkly with this technique. B, A 4-mm diameter plug of carcinoma that has been neatly plucked from the field shown in A. C, A histologic section of this plug. The specimen was embedded at an angle, and the original surface shown through the dissecting microscope in $B$ is the surface that faces the upper right in $C$.

Figure 2.

Appearance of benign prostatic tissue under the dissecting microscope. The tissue is from another area of the prostate in Figure 1. Only benign prostatic tissue is seen, characterized by large grouped glands. A, Arrows outline an area sampled as benign prostatic tissue. B, The 4-mm diameter plug of benign prostatic tissue procured. C, A histologic section of the procured tissue.

Figure 3.

Positive margin identified with the dissecting microscope. A, An area of carcinoma abuts a yellow-inked margin. Although hard to photograph because the tissue is not planar, infiltrating small glands can be seen to abut the yellow ink- and Bouin-treated surface at the top. This area was not grossly suspected before the tissue was stained and viewed with the dissecting microscope. B, A histologic section directed to this area documents the positive margin.

Figure 4.

A, Cytokeratin AE1/3 immunostaining of prostatic epithelial cells isolated and cultured from normal prostate tissue procured with the dissecting microscope. B, As a control, NIH3T3 cells (mouse fibroblasts) fixed and immunostained identically with the cytokeratin AE1/3 antibody show no staining. 
with the aid of the dissecting microscope contained only benign prostatic glands without high-grade prostatic intraepithelial neoplasia. One case showed foci of carcinoma with a pseudohyperplastic pattern, characterized by the presence of a few relatively large glands. One case showed high-grade prostatic intraepithelial neoplasia. One case, a radical cystoprostatectomy for bladder carcinoma, showed transitional cell carcinoma in situ extending into the presumed normal prostatic tissue.

\section{Effect on Final Pathologic Assessment}

The dissecting microscope allowed extraprostatic extension, or positive inked resection margins, to be correctly predicted in three cases (Table 1 and Fig. $3 \mathrm{~A})$, based on the presence of small glands infiltrating fat or abutting the inked capsule. These areas were not grossly evident. The findings led us to submit directed histologic sections during the tissue procurement procedure (Fig. 3B), thereby preventing the possible banking of these important areas.

\section{Test of Viability of the Procured Samples}

To test whether viability of the sample is maintained through the inking, mordant treatment with Bouin's solution, toluidine blue staining, and manipulations under the dissecting microscope, we procured additional samples of benign prostatic tissue from five prostatectomies after the foregoing diagnostic samples had been obtained. A previously published protocol was used (Webber, 1988) with minor modifications. Outgrowths of epithelial-appearing cells occurred in all five samples. No special sterile precautions were taken except that the toluidine blue was sterile filtered and aliquotted for use, instruments were dipped in alcohol and rinsed with tap water, and penicillin and streptomycin was used in the final culture media (see "Materials and Methods"). In spite of the lack of sterile technique, contamination in the form of fungal infection developed in only one of the five cultures.

The tissue culture technique (Webber, 1988) allows separation of epithelium from stromal cells and favors survival and growth of epithelium (Webber, 1988). The slow sedimenting final stromal fraction contained $90 \%$ stromal cells, as assessed by Papanicolaou staining. By ethidium bromide/acridine orange staining as a measure of viability (Coligan et al, 1992), less than $10 \%$ of the stromal cells were viable in two different purifications. The final epithelial cell fraction that is plated contains at least $50 \%$ epithelial cells, recognizable as broad two-dimensional sheets, of which $80 \%$ were viable as determined by ethidium bromide/acridine orange staining of two different isolates. The morphology of the final epithelial fraction does not change during the digestion and is identical to what would be seen in a scrape preparation of prostate: by Papanicolaou staining the final epithelial cell fraction shows broad sheets of cells with inconspicuous nucleoli, cuboidal cytoplasm, and spherical nuclei. To confirm that the epithelial cell fraction was successfully isolated from stroma, an early passage of cells was stained for cytokeratin AE1/3 and PSA. Strong cytokeratin staining was observed in more than $99 \%$ of the cells (Fig. 4A) compared with absent staining of control NIH3T3 cells (Fig. 4B) and control dishes of prostate cells in which no primary antibodies were used. Very weak specific PSA staining was also observed in the prostatic epithelial cells.

\section{Discussion}

Several authors have expressed concern that procuring prostate tissue for research runs counter to the needs of patients for an accurate pathologic diagnosis (Bova et al, 1993; Furman et al, 1998; Wheeler and Lebovitz, 1994). The concern is that small cancers may be totally procured, or that margins of resection can be disturbed during fresh tissue manipulation. To avoid the possibility of giving away all of the diagnostic carcinoma, some pathologists only advise procurement of prostate cancer when it is sufficiently advanced to be grossly suspected (Bova et al, 1993; Wheeler and Lebovitz, 1994). Studying early events in prostate cancer development has been particularly difficult for researchers. Except for microdissected samples, current procurement protocols are essentially unable to isolate small cancers at early stages of prostate cancer development. Because prostate carcinomas can be identified with high accuracy with the dissecting microscope, we believe that the dissecting microscope procedure will allow even very small prostate cancers to be safely sampled for research. A portion of even a very small cancer can be accurately left with the specimen for histologic study. In addition, we believe tissue procurement may actually promote high-quality pathologic assessment because extraprostatic extension and positive margins can be identified at the time of procurement and allow carefully directed histologic sections.

Beyond the reluctance to give prostate tissues to cancer researchers, there has been a difficulty in characterizing the tissue that ultimately falls into the hands of researchers. Viable tissue samples have been particularly difficult to procure, although viable samples offer important advantages for researchers. First, unfrozen tissue appears superior to frozen tissue for isolating intact RNA (Wheeler and Lebovitz, 1994). Second, only viable tissue samples allow dynamic types of studies to be performed. Third, only fresh viable tissue can be separated into bulk populations of epithelium and stroma. Bulk samples are required for static biochemical studies and for making nonamplified representative cDNA libraries (Freeman et al, 1999). To date, nonamplified libraries remain far superior to amplified libraries for comparative genome hybridization protocols or microchip molecular profiling (Emmert-Buck et al, 2000). The consequences of the inability to precisely characterize samples given to researchers are significant. For example, a high proportion of cytogenetic studies have found diploid karyotypes, but it is not clear if the karyotypes are 
Table 1. Histologic Diagnoses of Biopsies Obtained with the Aid of the Dissecting Microscope (DM) from Ostensibly Malignant and Benign Areas

\begin{tabular}{|c|c|c|c|}
\hline \multirow[b]{2}{*}{ Case } & \multicolumn{2}{|c|}{ Histologic Diagnosis } & \multirow[b]{2}{*}{ Notes } \\
\hline & Adenocarcinoma by DM & Benign by DM & \\
\hline 1 & Adenocarcinoma & Benign & Extra-prostatic extension correctly identified. \\
\hline 2 & ND (Not done; see note) & Benign & No definite cancer seen. \\
\hline 3 & ND (See note) & Benign & No definite cancer seen. \\
\hline 4 & ND (See note) & Benign & No definite cancer seen. \\
\hline 5 & Adenocarcinoma & Benign & \\
\hline 6 & Adenocarcinoma & Benign & \\
\hline 7 & ND (See note) & Benign & No definite cancer seen. \\
\hline 8 & Adenocarcinoma & ND (See note) & $\begin{array}{l}\text { Extra-prostatic extension into fat correctly identified. Not enough } \\
\text { normal in periphery to sample. Successful culture of benign } \\
\text { prostatic tissue from transition zone. }\end{array}$ \\
\hline 9 & ND (See note) & Benign & No definite cancer seen. \\
\hline 10 & Adenocarcinoma & ND (See note) & Too much cancer in peripheral zone to be able to procure normal. \\
\hline 11 & ND (See note) & Benign & $\begin{array}{l}\text { No definite cancer seen. Cystoprostatectomy for bladder cancer and } \\
\text { no prostate cancer was found histologically. }\end{array}$ \\
\hline 12 & Adenocarcinoma & Benign & Successful culture of benign prostate tissue. \\
\hline 13 & Adenocarcinoma & Benign & \\
\hline 14 & ND (See note) & Transitional cell CIS & $\begin{array}{l}\text { No definite cancer seen. Cystoprostatectomy for bladder cancer } \\
\text { with extension of transitional cell CIS into prostate. }\end{array}$ \\
\hline 15 & Adenocarcinoma & ND (See note) & Too much cancer to procure benign. \\
\hline 16 & Adenocarcinoma & Benign & \\
\hline 17 & Adenocarcinoma & Adenocarcinoma & $\begin{array}{l}\text { Focal hyperplastic type of large gland prostatic adenocarcinoma } \\
\text { present. }\end{array}$ \\
\hline 18 & ND (See note) & ND (See note) & $\begin{array}{l}\text { Extensive atrophy precluding procurement, confirmed in histologic } \\
\text { sections. }\end{array}$ \\
\hline 19 & Adenocarcinoma & Benign & \\
\hline 20 & Adenocarcinoma & Benign & \\
\hline 21 & Adenocarcinoma & Benign & $\begin{array}{l}\text { Pictures taken (Figs. 1-2). Extension to inked resection margin } \\
\text { observed and photographed (Fig. 3). }\end{array}$ \\
\hline 22 & Adenocarcinoma & High-grade PIN & $\begin{array}{l}\text { Benign sample had focal high-grade PIN. Separate sample of } \\
\text { "benign" prostate procured for successful culture and } \\
\text { immunostaining (Fig. 4). }\end{array}$ \\
\hline 23 & Adenocarcinoma & ND (See note) & $\begin{array}{l}\text { Not enough peripheral zone to procure benign prostatic epithelium. } \\
\text { Benign prostatic tissue from transition zone was procured for } \\
\text { cell culture but developed fungal contamination. }\end{array}$ \\
\hline 24 & Adenocarcinoma & Benign & $\begin{array}{l}\text { Successful culture of sample of benign prostatic tissue. Viability } \\
\text { assessed with acridine orange and ethidium bromide. }\end{array}$ \\
\hline 25 & Adenocarcinoma & Benign & \\
\hline
\end{tabular}

from benign epithelium or from stroma (Bright et al, 1997; Konig et al, 1998). It has been difficult to develop in vitro models of early human prostate cancer or to interpret published tissue culture studies because the diagnosis in the researcher's starting material may not be known (Planz et al, 1999; Sensibar et al, 1999).

In our study we successfully isolated epithelium from stroma using a simple protocol with collagenase digestion to disperse stromal cells into a slowsedimenting single-cell suspension. Epithelium remains as fast-sedimenting broad sheets (Webber, 1988). Protocols using Percoll gradients appear to be superior to the simple sedimentation protocol we used in achieving separation (Kassen et al, 1996; Sherwood et al, 1989). As tissue culture requirements of stromal and epithelial cells become better characterized, we envision it will be possible to adapt the dissecting microscope technique for safely deriving bulk, virtually pure, viable populations of either stroma or epithelium. Further, these two fractions should be derivable from either benign or carcinomatous prostate tissues.

The usefulness of this procedure is not limited to procuring viable samples. The technique should also facilitate safe and easy banking of well-characterized frozen samples.

A limitation of the dissecting microscope procedure is that presumably benign samples may contain architecturally sneaky cancer. The technique demands a solid knowledge of histopathology, and it requires practice. It may not be feasible for nonpathologists. Procurement of benign prostatic tissue should probably be attempted only in cases with a low volume of carcinoma. In our study, $85 \%$ of the samples diag- 
nosed as benign were free of cancer or of high-grade prostatic intraepithelial neoplasia. Estimates of the accuracy of a gross diagnosis of benign prostatic tissue range from $60 \%$ to $100 \%$, but it is not clear if these estimates include only transition-zone prostatic tissue (where cancer is less prevalent). We deliberately tried to sample peripheral zone tissue in our study. Neither is it clear from previous studies whether high-grade prostatic intraepithelial neoplasia discounted a sample from being considered benign (Bright et al, 1997; Wheeler and Lebovitz, 1994). High-grade prostatic intraepithelial neoplasia appears difficult to detect with the dissecting microscope, but it may be possible to develop criteria for its recognition in the future. For example, usual-type ductal hyperplasia of the breast appears distinguishable from normal ductal epithelium or ductal carcinoma in situ using the dissecting microscope (Fischer and Bouc, 1991). The finding of cytologic features of high-grade prostatic intraepithelial neoplasia (eg, in a touch prep or in a final cytologic sample of the isolated epithelium) in an architecturally noninvasive prostate tissue sample should predict the presence of high-grade prostatic intraepithelial neoplasia.

Toluidine blue is relatively nontoxic (Dunipace et al, 1992) and is used clinically to detect cancer in the oral mucosa and vulva (Joura et al, 1998; Mashberg and Samit, 1995). Toluidine blue has some mutagenic potential in the Ames test (Dunipace et al, 1992). In our study, the toluidine blue does not penetrate into the tissue very far, and it remains associated with the tissue on the very surface even during digestion; we do not know if these surface cells are killed by the toluidine blue. This technique is analogous to the use of methylene blue and a dissecting microscope to detect aberrant crypt foci (Bouzourene et al, 1999). Toluidine blue appears equally useful in evaluating colonic tissue with a dissecting microscope (Fischer and Bouc, 1991). We suspect that methylene blue would be interchangeable with toluidine blue for evaluating prostatic tissue samples.

The ability to procure viable samples of prostate cancer with great precision, together with evolving tissue culture methods for separating stroma from epithelium, should open the door for a new generation of dynamic studies of this most common cancer of men.

\section{Materials and Methods}

\section{Tissue Handling and Staining}

Emory University Human Investigations Committee approval for this study was obtained. Twenty-five consecutive radical prostatectomy specimens were inked with yellow and black ink on the left and right sides and blotted briefly with Bouin's solution (Prophet et al, 1992) to prevent the ink from smearing. Two complete crosssections (3- to 5-mm apart and parallel to each other) were made in the horizontal plane roughly equidistant from apex and base in an area in which the capsule showed no artifactual tearing. The resulting 3- to 5-mm thick tissue slab was stained on both sides with $0.5 \%$ aqueous toluidine blue (Fisher Biotech, Pittsburgh,
Pennsylvania) using a clean camel hair brush. Normal saline was used to rinse away the excess toluidine blue. A Nikon dissecting microscope with a $35-\mathrm{mm}$ camera $(\mathrm{SMZ}-2 \mathrm{~T})$ providing $10 \times$ to $63 \times$ magnification was used to examine the cut surfaces, as described previously (Fischer and Bouc, 1991). For each case, areas that appeared unequivocally benign or unequivocally malignant were procured with a 4-mm punch biopsy under guidance of the dissecting microscope, and one hematoxylin and eosin-stained paraffin section was prepared from each biopsy. For the benign samples, peripheral zone rather than transition zone tissue was acquired if possible. Except that three prostates were known to be part of a cystoprostatectomy for bladder carcinoma, there was no preconception about the amount, grade, or location of any tumor. The results of previous biopsies, serum prostatic specific antigen (PSA) measurements, or ultrasound examinations were not known at the time of procurement.

\section{Tissue Culture}

Punch biopsies of normal prostate tissue were procured for tissue culture using a modified protocol that separates stromal cells from epithelium (Webber, 1988). The tissue procured for culture was stained with sterile-filtered aliquots of $0.5 \%$ toluidine blue using a camel hair brush that had been dipped in $95 \%$ alcohol and rinsed under tap water, and a sterile 4-mm punch biopsy was used. These prostates had been inked with non-sterile yellow and black tissue marking ink, blotted with Bouin's solution, and a clean but non-sterile knife was used to section the gland. Tissue samples (40 to $60 \mathrm{mg} / \mathrm{sample}$ ) were rinsed in several milliliters of ice cold RPMI (CellGrow; Mediatech, Herndon, Virginia) from 30 minutes to 1 hour after the prostate was removed from the patient. The tissue was minced with fine scissors and placed in a 50-ml tube containing $5 \mathrm{ml}$ of digestion media. The digestion media contained RPMI media with 5\% FCS (Atlanta Biologicals, Norcross, Georgia), $100 \mathrm{U} / \mathrm{ml}$ penicillin, $100 \mathrm{U} / \mathrm{ml}$ streptomycin (both from CellGrow, Mediatech), and $400 \mathrm{U} / \mathrm{ml}$ collagenase (Sigma catalogue C-5138, from Clostridium histolyticum, Sigma, St. Louis, Missouri). The sample was digested in a humidified incubator with $5 \% \mathrm{CO}_{2}$ for 48 hours with occasional vigorous shaking. Two hours before the end of the digestion, the tissue was pipetted vigorously for about 1 minute to break it up. The stromal cells separate into a single-cell suspension and the epithelium remains as larger sheets, allowing their partial purification by differential settling. After 2 hours, the sample was transferred to a $15-\mathrm{ml}$ tube and pelleted gently three times by centrifugation at $290 \times g$ for 10 minutes, with resuspension of the pellet in $5 \mathrm{ml} \mathrm{Hank's}$ balanced salt solution. One final settling of the resuspended pellet in $5 \mathrm{ml}$ final growth media (RPMl with $10 \% \mathrm{FCS}$, and $100 \mathrm{U} / \mathrm{ml}$ each of penicillin and streptomycin) was performed, without centrifugation, for 10 minutes. The loose pellet was then plated in $2 \mathrm{ml}$ of final growth media in a $35-\mathrm{mm}$ Falcon plastic dish. After 2 to 3 days, adherent cell clusters were washed 
with PBS and fed final growth media twice per week. Aliquots of the final epithelial pellets and an aliquot of the stromal cell containing supernatant were removed for assessment of viability and cytomorphology. For assessing viability, cells were mixed into a solution of $50 \mu \mathrm{g} / \mathrm{ml}$ ethidium bromide (Amresco, Solon, Ohio) and $10 \mu \mathrm{g} / \mathrm{ml}$ acridine orange (Sigma, St. Louis, Missouri). Viable cells show acridine orange (greencolored) fluorescence; dead cells (in which membranes are permeable) stain bright red with ethidium bromide (Coligan et al, 1992). Morphology of the final cell fractions was assessed on standard alcohol-fixed Papanicolaou-stained Millipore filter preparations.

\section{Immunohistochemistry}

Immunohistochemistry was performed 1 to 2 weeks after seeding the culture, before passaging the cells. Dishes were rinsed with PBS and fixed with $10 \%$ neutral buffered formalin (Biochemical Sciences, Swedesboro, New Jersey) for 15 minutes at room temperature. The neutral buffered formalin was rinsed away with three washes of PBS and cells were permeabilized with $0.5 \%$ triton X-100 (Sigma) in PBS for 15 minutes. Mouse monoclonal AE1/3 antikeratin antibody (Dako Corporation, Carpinteria, California) and rabbit polyclonal PSA antibody (Dako Corporation) were used at 1:100 and 1:5,000, respectively. NIH3T3 cells (mouse fibroblasts) that were fixed identically were used as a negative control. Secondary reagents for detection of the primary antibody with streptavidin peroxidase and diaminobenzidine were used according to kit directions from Vector Laboratories (Burlingame, California) and included anti-Mouse kit (PK6102) and anti-Rabbit kit (PK-6101).

\section{Acknowledgement}

We are grateful to Robert Santoianni for his expert help in preparing the figures.

\section{References}

Bouzourene $\mathrm{H}$, Chaubert P, Seelentag W, Bosman FT, and Saraga E (1999). Aberrant crypt foci in patients with neoplastic and nonneoplastic colonic disease. Hum Pathol 30:66-71.

Bova GS, Fox WM, and Epstein JI (1993). Methods of radical prostatectomy specimen processing: A novel technique for harvesting fresh prostate cancer tissue and review of processing techniques. Mod Pathol 6:201-207.

Bright RK, Vocke CD, Emmert-Buck MR, Duray PH, Solomon D, Fetsch P, Rhim JS, Linehan WM, and Topalian SL (1997). Generation and genetic characterization of immortal human prostate epithelial cell lines derived from primary cancer specimens. Cancer Res 57:995-1002.

Coligan JE, Kruisbeek AM, Margulies DH, Shevach EM, and Strober W (1992). Quantitation of apoptotic index and cell viability using fluorescent dyes. In: Coligan JE, editor. Current protocols in immunology, vol 1. New York: Wiley Interscience, 3.17.1-3.17.4.

Dunipace AJ, Beaven R, Noblitt T, Li Y, Zunt S, and Stookey $G$ (1992). Mutagenic potential of toluidine blue evaluated in the Ames test. Mutat Res 279:255-259.
Egevad L, Engstrom K, and Busch C (1998). A new method for handling radical prostatectomies enabling fresh tissue harvesting, whole mount sections, and landmarks for alignment of sections. J Urol Pathol 9:17-28.

Emmert-Buck MR, Strausberg RL, and Krizman DB (2000). Molecular profiling of clinical tissue specimens: Feasibility and applications. Am J Pathol 156:1109-1115.

Fischer AH and Bouc M (1991). Usefulness of the dissecting microscope for diagnosis and teaching in surgical pathology. Surg Pathol 4:385-395.

Freeman WM, Walker SJ, and Vrana KE (1999). Quantitative RT-PCR: Pitfalls and potential. Biotechniques 26:112-122.

Furman J, Murphy WM, Rice L, Drew PA, and Narayan P (1998). Prostatectomy tissue for research: Balancing patient care and discovery. Am J Clin Pathol 110:4-9.

Joura EA, Zeisler H, Losch A, Sator MO, and Mullauer-Ertl S (1998). Differentiating vulvar intraepithelial neoplasia from nonneoplastic epithelial disorders: The toluidine blue test. J Reprod Med 43:671-674.

Kassen A, Sutkowski DM, Ahn H, Sensibar JA, Kozlowski JM, and Lee C (1996). Stromal cells of the human prostate: Initial isolation and characterization. Prostate 28:89-97.

Konig JJ, Teubel W, Kamst E, Romijn JC, Schroder FH, and Hagemeijer A (1998). Cytogenetic analysis of 39 prostate carcinomas and evaluation of short-term tissue culture techniques. Cancer Genet Cytogenet 101:116-122.

Mashberg A and Samit A (1995). Early diagnosis of asymptomatic oral and oropharyngeal squamous cancers. CA Cancer J Clin 45:328-351.

Planz B, Kirley SD, Wang Q, Tabatabaei S, Aretz HT, and McDougal WS (1999). Characterization of a stromal cell model of the human benign and malignant prostate from explant culture. J Urol 161:1329-1336.

Prophet EB, Mills B, Arrington JB, and Sobin LH (1992). Laboratory methods in histotechnology. Washington, DC: American Registry of Pathology.

Sakr WA, Grignon DJ, Visscher DW, Wolman SR, and Crissman JD (1995). Evaluating the radial prostatectomy specimen, part I. J Urol Pathol 3:355-364.

Sensibar JA, Pruden SJ, Kasjanski RZ, Rademaker A, Lee C, Grayhack JT, and Kozlowski JM (1999). Differential growth rates in stromal cultures of human prostate derived from patients of varying ages. Prostate 38:110-117.

Sherwood ER, Berg LA, McEwan RN, Pasciak RM, Kozlowski JM, and Lee C (1989). Two-dimensional protein profiles of cultured stromal and epithelial cells from hyperplastic human prostate. J Cell Biochem 40:201-214.

Suarez-Quian CA, Goldstein SR, Pohida T, Smith PD, Peterson JI, Wellner E, Ghany M, and Bonner RF (1999). Laser capture microdissection of single cells from complex tissues. Biotechniques 26:328-335.

Webber MM (1988). Normal, benign and malignant human prostatic epithelium: In vitro cell models for studies on the etiology, treatment, and prevention of benign and malignant human prostatic neoplasia. In: Webber MM and Sekely LI, editors. In vitro models for cancer research, vol 5. Boca Raton: CRC Press, 25-103

Wheeler TM and Lebovitz RM (1994). Fresh tissue harvest for research from prostatectomy specimens. Prostate 25:274-279. 